\title{
NATURALEZA Y VÍNCULOS SOLIDARIOS EN DOS TEXTOS INÉDITOS DE MANUEL ROJAS: ASTROMELIA Y "EL NIÑO Y EL CHOROY"
}

\author{
María José Barros \\ Universidad Adolfo Ibáñez \\ Santiago, Chile \\ mjbarro1@uc.cl \\ Pía Gutiérrez \\ Pontificia Universidad Católica de Chile \\ Santiago, Chile \\ gutierrezdiazpia@gmail.com
}

\begin{abstract}
RESUMEN / ABSTRACT
El objetivo del artículo es explorar cómo Manuel Rojas piensa, imagina y ficcionaliza las relaciones entre seres humanos y naturaleza en el marco de una sociedad en tránsito hacia la modernidad a partir de dos textos inéditos del archivo del escritor: el proyecto de novela inconclusa Astromelia y el cuento "El niño y el choroy". En ambos, Rojas nos sitúa frente a personajes que, inmersos en contextos vitales y culturales diversos, se vinculan afectivamente con seres vivientes tanto humanos como no-humanos. Más allá de las instituciones tradicionales del matrimonio y la familia o la afinidad política mediada por el anarquismo, estamos hablando de sujetos que establecen "parentescos raros" (Haraway) con otros -humanos, animales y plantas- sobre la base de la solidaridad y la reciprocidad. De esta manera, Rojas nos invita a pensar en pequeñas comunidades afectivas, colaborativas y móviles, en las que se entrelazan subjetividades heterogéneas, no necesariamente humanas.
\end{abstract}

Palabras clave: Manuel Rojas, naturaleza, animales, humanos, archivo, vínculos.

$1 \quad$ Algunas ideas de este texto, que nace del diálogo amistoso, se gestaron en la escritura para el dossier de Anales de Literatura Chilena dedicado a la figura del autor y coordinado por Fernando Moreno. 


\section{NATURE AND BONDS OF SOLIDARITY IN TWO UNPUBLISHED TEXTS BY MANUEL ROJAS: ASTROMELIA AND "EL NIÑO Y EL CHOROY”}

The aim of this article is to explore how Manuel Rojas thinks about, imagines, and fictionalizes the relationship between humans and nature in the context of a society headed towards modernity, using two unpublished texts from the writer's archive: the unfinished novel Astromelia and the short story "El niño y el choroy". In both, Rojas introduces us to characters who, immersed in vital and culturally-diverse contexts, bond effectively with living beings, both human and non-human. Beyond traditional institutions like marriage and family or a political affinity mediated by anarchism, we are talking about characters who make "oddkin" (Haraway) with others-humans, animals, and plants-on the basis of solidarity and reciprocity. In these texts, Rojas invites us to think about small, collaborative, and mobile affective communities, in which diverse subjectivities, not necessarily human, are intertwined.

KEYWORDS: Manuel Rojas, nature, animals, humans, archive, bonds.

Recepción: 27/01/2021

Aprobación: 09/02/2021

Recién, en los alrededores de Laguna Verde, cogí unas pálidas, desmayadas Alstroemerias. Pero ellas son vagabundas e inmortales, peregrinas -así las llaman- a lo largo de Chile, hasta volverse amancay en los caminos y boscajes del sur. Se alzan en corolas de tonos diferentes, desde las costas acantiladas de Tarapacá y Antofagasta o desde el hondón de las quebradas con grietas de humedad, hasta el extremo sur. Están mejor hechas que nosotros para la adaptación a los elementos. Si están ahora fatigadas, mañana volverán a brotar, suculentas, como en la espléndida ilustración que abre y cierra el hermoso libro de Carlos Muñoz Pizarro: Flores silvestres de Chile. No hay peligro de que desaparezcan.

Seguirán sin duda, más allá de nosotros.

(Oyarzún 53)

\section{INTRODUCCIÓN: ABRIENDO BROTES DESDE EL ARCHIVO}

El trabajo con el Archivo Manuel Rojas, en el cual hemos tenido la oportunidad de participar activamente desde el año 2017 gracias a la alianza entre la Sucesión Manuel Rojas, el Centro de Estudios de Literatura Chilena (CELICH) y la Biblioteca de Humanidades de la Universidad Católica, nos 
ha permitido indagar en nuevas facetas y entradas de lectura acerca de la obra de este escritor fundamental de la literatura chilena y latinoamericana del siglo XX. Más allá de la narrativa, género por el que se suele ingresar al proyecto escritural rojiano, los documentos reunidos en el archivo no solo nos enfrentan al laboratorio de escritura de Rojas, sino también a los diálogos que el autor de Hijo de ladrón estableció con otras disciplinas artísticas y soportes mediáticos como la radio, el cine, el teatro y la televisión; su trabajo como articulista en distintos periódicos nacionales; su constante preocupación por la premura económica y las condiciones materiales de la escritura; los viajes y textos como diarios, cartas o apuntes que emergen de estos desplazamientos por Chile y otros países del mundo; los proyectos creativos inéditos e inconclusos; y su pasión por la naturaleza, los pájaros y caminatas al aire libre.

Como bien señala Javier Guerrero en su estudio sobre los archivos de Severo Sarduy y Reinaldo Arenas, "el archivo tiene que ver con el exceso" (42). En el caso del archivo de Manuel Rojas, pensamos que este nos enfrenta a un exceso que amplía, diversifica y tensiona lo que hoy conocemos de la literatura rojiana, dando cuenta de una obra siempre abierta y en proceso, en la que Rojas se atrevió a ensayar distintas rutas, muchas de ellas desconocidas o escasamente estudiadas. El carácter procesual de la obra adquiere por lo mismo un mayor relieve, pues permite valorar dichos ensayos comprendiendo una orgánica de la escritura vinculada a la vida que nos deja atender las obras inconclusas o inéditas como una ampliación de las lecturas a literaturas ya canónicas como la de Rojas. Es así como el trabajo con archivos, por una parte, supone el resguardo patrimonial de los manuscritos del Premio Nacional de 1957, asegurando el cuidado y acceso público a materiales que se consideran fundamentales en la conformación identitaria de nuestra literatura $\mathrm{y}$, por extensión, de nuestros imaginarios. Esto último, porque configuran un panorama de enunciados posibles, en coherencia con lo propuesto por Foucault en Arqueología del saber (1969), al operar como repositorios de un saber que se generaliza olvidando su construcción cultural (arqueología) y pasando a ser el a priori histórico en la configuración de subjetividades. Por otra parte, el descubrimiento de nuevos escritos nos ha permitido detenernos en ensayos de una subjetividad que se vuelve significativa en el presente, en tanto una memoria activa que proyecta vías para desplazarnos al futuro, pues, como dice Wolfgang Ernst: "residential, static memories are being replaced by dynamic, temporal forms of storage in streaming media" $(\mathrm{s} / \mathrm{n})$. 
Considerando lo anterior, en esta oportunidad nos hemos propuesto explorar cómo Rojas piensa, imagina y ficcionaliza las relaciones entre seres humanos y naturaleza en el marco de una sociedad latinoamericana en tránsito hacia la modernidad a partir de dos textos inéditos encontrados en el archivo: el proyecto de novela inconclusa Astromelia y el cuento "El niño y el choroy". En ambos escritos, Rojas nos sitúa frente a personajes que, inmersos en contextos vitales y culturales diversos, se vinculan afectivamente con seres vivientes tanto humanos como no-humanos. Más allá de las instituciones tradicionales del matrimonio y la familia o la afinidad política mediada por el anarquismo, estamos hablando de sujetos que establecen "parentescos raros" (Haraway 24) con otros -humanos, animales y plantas- sobre la base de la solidaridad, la reciprocidad y una especial valoración por la naturaleza y sus distintas formas de vida. De esta manera, Rojas se nos presenta como un escritor con una profunda vocación ecológica, manifiesta también en algunas crónicas del volumen A pie por Chile (1967) y una serie de artículos sobre aves que han ido reapareciendo gracias al archivo y el trabajo de Daniel Muñoz -nieto del autor- al respecto.

De acuerdo con la bióloga, antropóloga y filósofa feminista Donna Haraway, lo que actualmente necesitamos para enfrentar de forma activa la catástrofe ambiental provocada por el accionar humano es crear o bien reactivar lazos, vínculos y conexiones multiespecies que incentiven la colaboración de unos con otros: "Seguir con el problema requiere generar parentescos raros: nos necesitamos recíprocamente en colaboraciones y combinaciones inesperadas, en pilas de compost caliente. Devenimos-con de manera recíproca o no devenimos en absoluto" (24). En el caso de Astromelia, ese vínculo inesperado emerge de la fascinación de Pedro Orellana -una suerte de alter-ego del Rojas ya adulto- por la astromelia, planta que a su vez opera como un documento vivo del lazo amistoso y los intereses comunes entre Manuel Rojas y su entrañable compañero de vida José Santos González Vera. En "El niño y el choroy", por su parte, esta relación solidaria se forja entre Juan -un niño campesino-y un choroy herido, cuya vida decide defender y cuidar ante las amenazas de muerte de su padre y otros integrantes de la familia. En definitiva, ambos relatos dejan entrever la posibilidad de formar pequeñas comunidades afectivas, colaborativas y móviles, en las que se entrelazan subjetividades heterogéneas, no necesariamente humanas, que tensionan cualquier fantasía colectiva de uniformidad o pureza así como las relaciones promovidas por la modernización capitalista que implican la explotación y dominación del otro. 
Por cierto, parte de esta lectura se nutre de aproximaciones críticas en torno a la obra de Manuel Rojas que nos anteceden. En primer lugar, rescatamos de Grínor Rojo su idea acerca de la creación de una comunidad alternativa al orden burgués por parte de personajes como Aniceto Hevia, Cristián Ardiles y el Filósofo Echeverría en Hijo de ladrón, tema que también ha sido trabajado lúcidamente por Macarena Areco en relación con los espacios en la tetralogía rojiana y su categoría de la intemperie. En palabras del crítico chileno:

Los valores del sistema burgués no son los de esta comunidad [...]. Ni el trabajo, ni el dinero, ni la casa, ni la familia [...] ni la previsión del porvenir son consideraciones de importancia para Cristián, Echeverría $\mathrm{y}$, desde ahora en adelante, tampoco para Aniceto. Todo un programa, por lo tanto. Basado éste en la posibilidad de constituir comunidad al margen del paradigma sistémico, el estatista, el conyugalista, el familiarista, el paternalista y el maternalista burgués (Rojo 19).

De acuerdo con Rojo, lo que subyace a este tipo de comunidad son los ideales libertarios como "el rechazo de las ataduras, el aprecio por la libertad y por una comunidad de iguales cuya pertenencia uno escoge y desescoge libérrimamente" (19). En línea con lo anterior, y siguiendo ahora a Ignacio Álvarez y Stefanie Massmann, nos parece iluminadora su propuesta sobre el lugar central que ocupan los valores de "la solidaridad y fraternidad humanas" (8) en la creación de vínculos sociales en la primera narrativa de Rojas. Cuentos como "Laguna", "El delincuente" y "El vaso de leche" dan cuenta, según ambos críticos, de una ética de la reciprocidad, la justicia y la amistad que, al mismo tiempo, entraña una ética política en la que "el sujeto marginal también puede decidir" (18). En consecuencia, pensamos que la proyección utópica de comunidades alternativas, libertarias y solidarias también puede ser leída a partir de la genuina preocupación de Rojas por la naturaleza y otras formas de vida que circundan reiteradamente en su escritura. Ahora bien, nos parece importante mencionar que su vínculo con la naturaleza está mediado por sus ideales anarquistas, desde los cuales se defiende un estilo de vida al margen de todo tipo de disciplinamiento y que compete no solo a los hombres sino a mujeres, niños, pájaros, plantas y otros seres vivos en un compromiso que es también político y recíproco. 


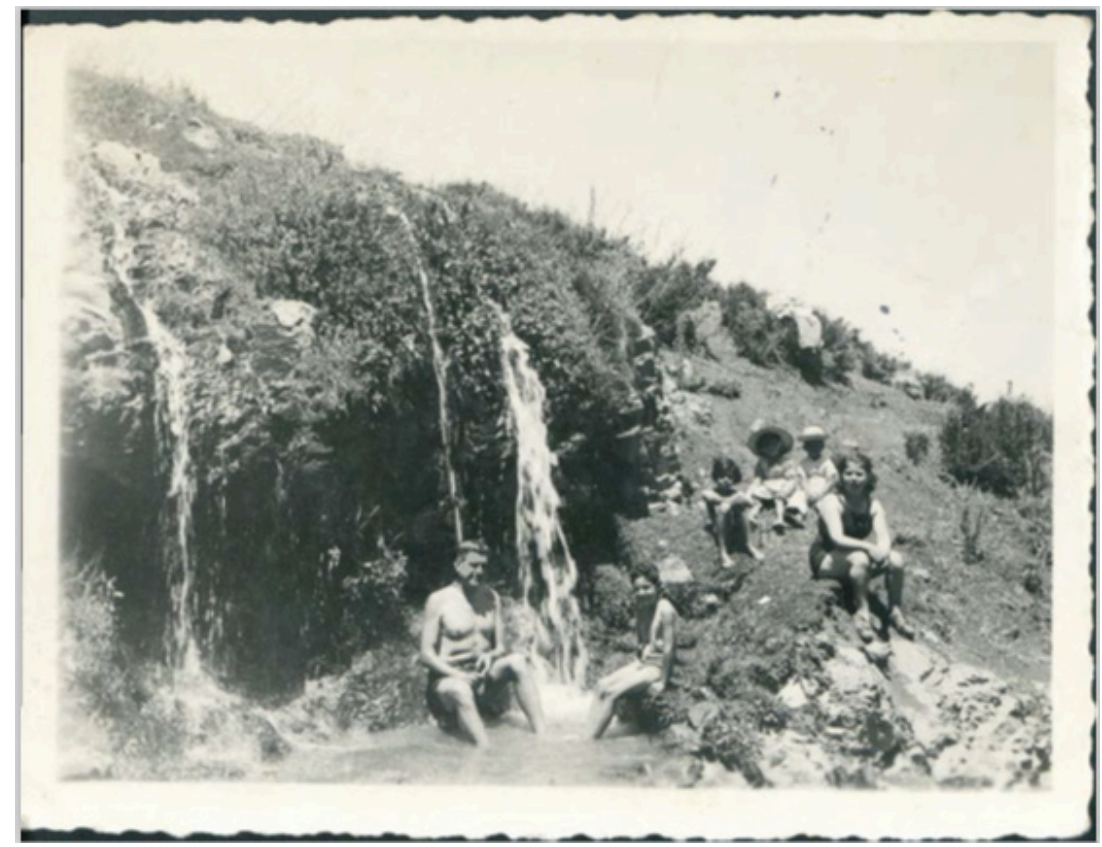

Manuel Rojas con sus hijos. Refugio Lagunillas, 1936.

Archivo Manuel Rojas

\section{ASTROMELIA: AMISTAD, CUERPO Y CAMINATA}

Enrique Espinoza (1898-1987) -escritor ruso-argentino, fundador de la revista Babel y amigo de Manuel Rojas-, relata en su libro dedicado a la vida del chileno: "Gran caminante, Manuel Rojas... Durante mi residencia trasandina me inició en este culto gorkiano. No se me olvidará nunca la ascensión hasta el refugio de Lagunillas, cerca del límite argentino. Iban con nosotros nuestras mujeres y también mi vástago, entonces de apenas cinco años" (28). Sobre esas caminatas en las que participó, más adelante indica:

No fueron muchas, sin embargo, las correrías que hicimos con el formidable andinista a quien llamó Waldo Frank: el andariego Sherwood Anderson del Sur. Puedo recordar apenas unas cuantas salidas rurales, una en que dormimos en carpa junto al mismo límite de Mendoza y otra, en compañía del humorista González Vera, tan 
urbano como yo mismo, en busca de la astromelia, flor difícil de hallar cuando se sale a buscarla y que de pronto se la encuentra cuando menos se piensa (28).

De esa astromelia que Rojas buscaba con sus amigos, Paz Rojas, hija menor del autor, cuenta que encontrarla se convirtió en una obsesión para su padre, y que esa búsqueda fue una tarea que no emprendió solo sino con su amigo José Santos González Vera, como bien indicara Espinoza en su recuerdo de las caminatas cordilleranas. Según el relato de Paz Rojas, la fotografía de la astromelia que se guardaba en el escritorio de su padre fue un regalo que le hizo Santos Vera y que usaban como guía de caminatas. Este relato ha alcanzado una pequeña mitología, que Jorge Guerra -presidente de la Fundación Manuel Rojas- transmite con entusiasmo, pues la imagen que envejeció en la que fue la casa del autor encuentra eco en un manuscrito inédito del Archivo Manuel Rojas.

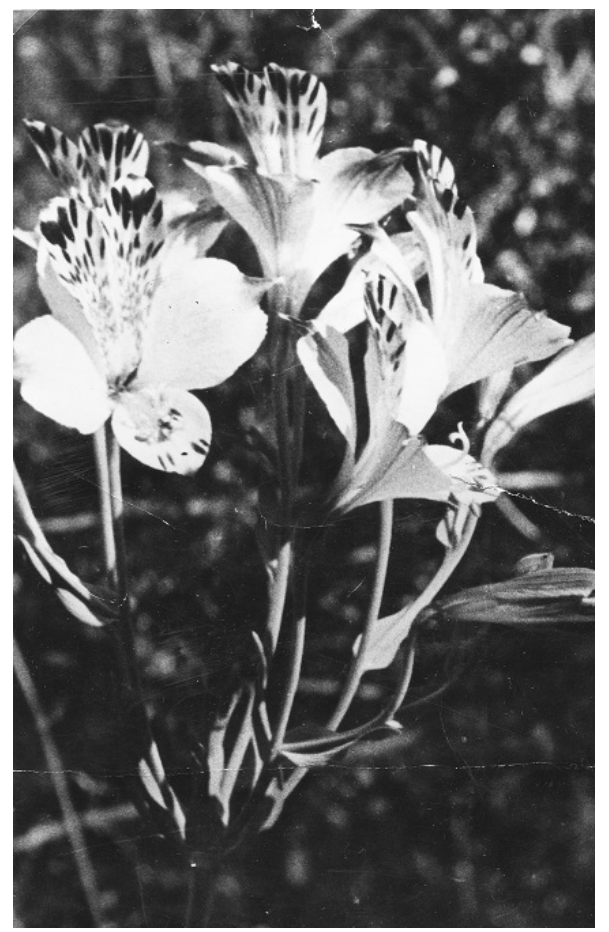

Fotografía de una astromelia que guardaba Rojas en la cubierta de su escritorio. Gentileza de Daniel Muñoz. 
Entre los materiales del archivo de Rojas, uno de sus cuadernos conserva lo que podría haber sido el primer capítulo de la novela Astromelia. El manuscrito parte así:

En esta casa hay, casi siempre, alguien que habla, que mueve una silla, suelta el agua del baño o pasa la enceradora; una que otra vez, sobrecogiéndolo, suena el teléfono o estalla el llanto de un niño. En este instante, sin embargo, y desde hace un largo rato, no se oye nada, y Pedro, que estaba con los antebrazos afirmados en el escritorio, inclinada la cabeza y mirando hacia alguna parte, sin ver nada, está aún así, aprovechando el instante de silencio. Times Square! Change to local! El grito del hombre del subterráneo lo sustrae del ensueño y lo trae a la realidad y ve, bajo el cristal de la cubierta del escritorio, la fotografía de la Alstroemeria Pulchra (2).

Esa flor en el escritorio trae una y otra vez a este personaje, Pedro Orellana, a la obsesión que ha cultivado por la escritura. Una especie silvestre, de la que muchas variedades existen solo en $\mathrm{Chile}^{2}$, se le ha revelado gracias a los conocimientos de un botánico norteamericano, mezclándose con una escena en el metro de Nueva York, mientras en su bulliciosa casa en "un barrio de Santiago" intenta escribir, quizás, el mismo texto que estamos leyendo. La fotografía de la flor, no solo la flor misma sino su imagen, adquieren en este proyecto un carácter performativo, que activa un cuerpo caminante y amistoso, un cuerpo que cómplice se entrega a la escritura y la experiencia del escritor en una suerte de búsqueda. La especie que ocupa el lugar central de este capítulo inédito es muy común para los campesinos pero desconocida para los letrados. Ahí mismo parece recaer una clave en la figura del escritor que proyecta este narrador que se posiciona a medias aguas entre lo local y lo global, la montaña en que supone se encuentra la astromelia y el metro de Nueva York, la vida doméstica y el viaje solitario.

\footnotetext{
Ernesto Wilhelm de Mösbach indica sobre esta flor en su libro Botánica indígena de Chile: "El género Alstroemeria tiene vasta diferenciación en Chile, cuenta con más de cincuenta especies, de una sistemática bastante intrincada. Los mapuches dan el nombre de Rayen-cachu: hierba en flor, a sus representantes. Los chilenos del sur (Osorno) designan como amancay algunas de estas especies (A. aurantiaca D. Don. y A. haemantha R. et. P.); en el norte (La Serena) llaman "lirio" a la espléndida Alstroemeria violacea Phil., especial adorno de la península Punta Teatinos" (69, negritas en el original).
} 
A partir de estas imágenes se despierta la curiosidad de especular sobre el vínculo amistoso de Manuel Rojas y José Santos González Vera, y a su vez la extensión de ese vínculo a la flora de un territorio. En ese triángulo se puede leer una filiación electiva que propone una caracterización del escritor de su época vinculado a la capacidad de experimentación que los sujetos narradores tienen. En este sentido, el cuerpo y la escritura se conectan en experiencias compartidas como el caminar y explorar la naturaleza atribuidos a marcos para afrontar la vida y el arte, expandidos por pensadores como Henry David Thoreau, muy populares entre los anarquistas de principios del siglo XX. Así, la imagen de la astromelia descrita en este proyecto nos permite revisar algunas posibilidades de la representación corporal en el proyecto escritural de Rojas y su relación con los vínculos raros de los que hemos venido hablando.

En Astromelia, el narrador expresa el descontento y sorpresa por la ignorancia en que Pedro se encontraba, un estado de ignorancia que no logra entender y que se ve remediado por un gesto amistoso:

¿Y por qué ningún botánico chileno le había hablado de ella? La buscó: había por todas partes en las quebradas de la Cordillera de la Costa y entre las piedras de la de los Andes, en las arenas de las playas marítimas, entre el trumao de los volcanes y al borde de los glaciares de Tierra del Fuego, cada una con una propia forma y propio color, dorada, violáceas, lilas, purpúreas, achaparradas o erguidas, recoletas o gregarias, y se llamaban Peregrinas, Legariñas, Flores del Águila o Mariposas del Campo.

Un amigo, finalmente, le regaló la fotografía de una Alstroemeria Pulchra, y ahí está bajo el cristal, con su tallo glabro y su umbrela de pocas flores (Astromelia 3-5).

Dicho amigo, ante la desesperada búsqueda, le da un indicio, una imagen que le permite continuar esperanzado en conocer, en encontrar la flor y a la vez emprender la reflexión que comparte en la escritura. A diferencia del botánico norteamericano, conocedor teórico y foráneo, el amigo es capaz de entregarle un objeto que acompaña sus labores en el escritorio, espacio íntimo vinculado al mundo privado de la casa como bien se describe al inicio del capítulo. En este breve relato se construye la persecución del deseo de un conocer que parece vetado para quien escribe. La acumulación de datos en torno a la flor -nombre con que se la conoce, territorios en que crece y características anatómicas- suponen alejar más y más la experiencia de 
encontrarla. Atendiendo a la historia de Paz Rojas, ese amigo podría ser un alter ego de Santos Vera e incluso si no fuera así, la elección narrativa de asignar esta revelación a un amigo, vínculo libre por elección y afinidad, refuerza lo bien ponderada de estas alianzas en el texto.

La amistad es necesaria para el conocimiento, ya sea al entregar la fotografía de la astromelia al interior del relato y así abonar a la búsqueda del escritor, o por la declarada filiación que da el trabajo de escritor como un oficio más entre las agrupaciones obreras. A propósito escribe Rojas para el cumpleaños número 59 de Antonio Acevedo Hernández:

[Q]uisiera que le llegara testimonio de mi amistad y de mi compañerismo... El escritor es como un obrero de obra fina, un zapatero o un mueblista: trabaja, crea... Moriremos, Antonio, como esos obreros, con la herramienta en la mano (Rojas s/n).

La amistad da al sujeto un sentido de pertenencia que Rojas llama compañerismo. Entender a estos escritores como vértice en una generación autodidacta y militante implica reconocerlos como sujetos híbridos que transitan entre los procesos de modernización de principios del siglo XX. Esta configuración del escritor repercute precisamente en que además de transitar entre el mundo obrero y el letrado, o de entender la literatura como un oficio, flexibilizan vínculos que representaban unidades mínimas de la organización estatal como la familia. Si bien se habla de hijos y de hogares, los personajes de Rojas son solitarios que deciden unirse a personas por afinidad y en ese sentido la amistad cobra protagonismo pues es un vínculo abierto, mucho más ligero que el amor o los vínculos de sangre, y que permite múltiples cruces a diferencia de las otras relaciones. La mención de este amigo que en Astromelia es dador de la imagen puede leerse, entonces, como una referencia alegórica que se extiende una visión del mundo y a un sistema de valores que prevalece en la literatura rojiana.

Este saber unido a la vivencia de la naturaleza está marcado por la exploración. El escritor no cultiva ni pretende cultivar la astromelia, sino encontrarla en su hábitat. Como contrapunto, Rubí Carreño nos proporciona una visión del cultivo de plantas y la relación con el mundo vegetal, a partir de la representación de la huerta en la poesía escrita por mujeres:

La huerta, el jardín, también el menoko, es decir, el humedal donde crecen las plantas medicinales, el bosque, serían lugares en que el encuentro con lo sagrado estaría favorecido por la presencia bienhechora 
de las plantas. En estos espacios, donde la vida canta por la presencia de abejas y pájaros (como en el poema de Urriola) se posibilitarían los viajes entre el cielo y la tierra, con la felicidad y facilidad en que pájaro sube y baja de su nido (Carreño 168).

En los poemas de Gabriela Mistral y Malú Urriola, la huerta es el dominio femenino en que mujer y plantas se armonizan en una relación mutualista. El conflicto del hombre representado en Rojas es su desconexión con el mundo natural y en particular con esta flor que le devuelve la imagen, una especie de ceguera que tiene una salida esperanzadora cuando vemos transitar la imagen de la flor al recuerdo del cuerpo de Jane, al vínculo de la amistad y luego a relación con los pájaros como si en ese paralelo el mundo se reorganizara y el hombre encontrara un lugar ya no dominante ni dominado, sino libre e igualitario.

Desde estas relaciones, volvemos sobre la foto de la astromelia. El narrador desconoce esta planta y su anhelo de encontrarla abre sus sentidos y su experiencia sobrepasa lo presencial y concreto dotando a la imagen de una condición performativa que da pie a la acción y al hacer del sujeto narrador. Esta imagen, dice Andrea Soto Calderón, es reproductiva y productiva a la vez:

Un nuevo medio crea una nueva forma de sensibilidad, abre una nueva forma de experiencia. La fotografía no solo es la invención de un medio de reproducción, si no la textura de un mundo: una constelación entre percepción, experiencia y técnica, una inervación... la fotografía también inaugurará nuevos desafíos para la mirada y para la creación, como diría John Berger en Otra manera de contar, "la ambigüedad de la fotografía surge de esa discontinuidad que da lugar al segundo de los mensajes gemelos de la fotografía. El abismo entre el momento registrado y el momento de mirar" (63).

La fotografía de la astromelia es un objeto mágico para abrirse a otro saber y encarnar ese conocimiento del que se habla. Al mirar la fotografía el narrador se desvía y, en una narrativa sin aviso, pasa de la imagen a una sombra que encuentra su visión periférica. Al dejar vagar el ojo, se amplía también su pensamiento y su cuerpo: vuelve a la casa, al parrón y a la uva del vecino que imagina ya estará madura. La divagación del lenguaje acompaña al pensamiento y al vagar de un cuerpo que se imagina en movimiento a partir de la observación de la imagen estática, muy distante de la flor real, que está en su escritorio: "Estira el cuello para contarla y en ese momento una sombra se mueve en el límite más bajo y lejano de su campo visual” (7). El cuerpo 
se estira en disposición a la búsqueda. En esta vía podemos vincularlo a la repetida experiencia de los personajes en Rojas, principalmente masculinos, para quienes el movimiento es la seña de esa libertad tan ansiada. El texto avanza construyendo un continuo que nos lleva hasta el dueño de la sombra, un zorzal, que hace a Pedro recordar un pájaro en Puerto Rico y luego al otoño, estación en que nos dice llegó a Nueva York y finalmente hasta Jane, específicamente hasta las piernas de Jane, mujer que encarna el segundo y paralelo deseo del narrador: "no sabe aún si cuando Jane lo miraba y le hablaba si era porque resultaba natural que lo hiciera, arrastrada por la pasión del momento, o porque quería provocar en él una fijación. "Pedro, Pedro..." Era un susurro y pareció quedar pegado, durante muchos días, en el oído, tal como la mirada quedó en los ojos" (11).

El cuerpo aparece fragmentado, dislocado en la experiencia sorpresiva del que narra, no como un todo cerrado y clausurado, sino como un lugar de constante construcción en relación con lo que experimenta. Tanto como la anatomía de la flor es analizada en detalle al principio del relato, el cuerpo del narrador se fragmenta en el recuerdo de Jane para focalizarse en las piernas de esta mujer y en su voz, otra vez un cuerpo disociado al que no se puede tener acceso por completo. En todo ese divagar, es la foto de la astromelia la que acciona el reconocimiento de los sentidos y su distribución en las palabras.

Lorena Amaro lee a Rojas y González Vera como escritores pasadores de fronteras en el campo literario de su tiempo, pues concibe como pasador, retomando a Castillo, "la figura de aquel "que pasa y hace pasar consigo entre un territorio y otro" los contenidos simbólicos en tránsito durante el periodo de modernización vivido en Chile entre 1891 y 1920" (21). Esta condición puede extenderse a la apreciación de estos sujetos de y con la naturaleza. Así, la figura de Rojas y su expresión literaria se construiría como un vértice para un punto de vista intermedio en su relación con el entorno. Si retomamos la trayectoria territorial en ambos autores, dada por su condición de migrantes (campo-ciudad para González Vera y trasandino en Rojas), se amplía esta idea de pasaje a la construcción de una subjetividad en el entre, en un estar siendo más procesual que fijo, más colectivo que individual y que encuentra lugar en una estructura narrativa. Es en ese marco que la amistad se muestra como un núcleo vital que traspasa oficios, promueve la escritura y el conocer, y media las jerarquías como asuntos que son centrales en Astromelia.

Otro aspecto a considerar en la trayectoria de los cuerpos en Astromelia es el deseo de caminar. Tanto en la narrativa como en la escritura autobiográfica rojiana, se reproduce un estatuto basal de los vínculos amistosos en un espacio 
natural mediado por el caminar. En cuanto al caminar, si bien no existe una caminata real en la narración del primer capítulo de Astromelia, se evoca el movimiento que nos lleva desde el escritorio a la búsqueda de la flor cruzada con el recuerdo de los ruidos de la ciudad en el metro de Nueva York hasta Jane. El movimiento está dado por la alternancia de espacios y pensamientos que recorren la escritura. Este texto inicial de lo que suponemos es un proyecto que no tiene continuidad en las preocupaciones de Rojas, nos deja a los lectores una pregunta precisamente sobre esa formación o conocimiento. El narrador desconoce la flor como parece desconocerse a sí mismo. Nunca supo de esta especie que tan bien conoce la gente del campo, quienes recorren el territorio tramo por tramo a pie y lo dominan. La sorpresa de la voz que narra se cruza con un nuevo descubrimiento, uno amoroso, que describe en fragmentos en medio del ensoñamiento que lo hace recordar a esta mujer deseada que está lejos. La perspectiva de la evocación alterna ritmos, el del jardín de la casa versus el del metro de Nueva York, hasta detenerse en el zorzal que da sombra a la fotografía y finalmente pasa de ahí a pensar en los pájaros de Estados Unidos y en los pájaros en general:

¿De dónde diablos salen? Los habíamos visto años atrás, en la Plaza del Capitolio, en la Habana, y en las orillas del Canal de Panamá. Eran como proletarios: salían temprano, quizá si al amanecer, hacia los campos, y regresaban solo en las tardes, todos juntos o en grupo, como obreros de una misma fábrica o peones de una misma hacienda (13).

Los pájaros se multiplican, tienen la libertad de estar en todas partes, a diferencia de la astromelia que se le ha mostrado esquiva y lejana. El narrador reconoce en los pájaros un espíritu común agregado en el movimiento y similar al de los obreros caminando agrupados al final de la jornada. La astromelia, como especie local, se aferra al terreno que debe ser explorado por el narrador, mientras que los pájaros parecen perseguir a Pedro. El deseo por aquello que le ha sido vetado en la presencia solo se concreta en la visión de la fotografía de su escritorio. Él como un escritor pasante habita la casa, pero rememora los viajes, el movimiento y a la mujer que ha encontrado en ellos. Esa fotografía desplaza la experiencia corporal, la desagrega, convirtiéndolo en partes desorganizadas. Antonia Viu nos propone que "la caminata en Rojas expresa la necesidad de orientarse sobre un territorio compartido con otros" (117). Si bien no hay caminata en lo narrado en el primer capítulo de esta novela inédita, nos parece interesante evocar esta acción como posible salida a la encrucijada del narrador. 
La admiración de Rojas por otros caminantes suma a esta idea del caminar como una posibilidad para clarificar la situación inicial del narrador en Astromelia y acercarse a la libertad que ansía. Acerca del "andarieguismo" propuesto por Pedro Prado, fundador del grupo Los Diez, señala Rojas:

Pedro Prado, poeta y prosista, gran escritor, habló una vez del "andarieguismo" y habló del "andarieguismo" o del andar como una doctrina del conocimiento o descubrimiento de la belleza, no solo de la belleza física, sino también de la belleza en sí, de la belleza creadora, pues andar, en el sentido que le daba Prado, incluye el pensar y el sentir (Rojas, "Rincones" 105).

Pensar y sentir que se clarifican en una nueva experiencia corporal, no ya la evocadora de performatividad en la potencia de la fotografía, sino en el movimiento corporal.

Los pájaros son libres, dice al final del texto. Su movimiento y constante migración otorgan esa libertad anhelada. Los hombres, y mujeres nos gustaría decir, caminan haciendo del viaje algo más importante que el destino, atravesando con su cuerpo unitario y gracias a la fuerza del mismo paisajes y tiempos que le dan consistencia a la subjetividad. Así lo confirma Rebecca Solnit en su libro Wanderlust. Historia del caminar: "El caminar comparte con el hacer y el trabajar aquel elemento crucial del compromiso del cuerpo y la mente con el mundo, el conocimiento del mundo a través del cuerpo y del cuerpo a través del mundo" (55). Si los pájaros vuelan como saliendo del trabajo, los humanos caminan. La inquietud de Astromelia está vinculada a la inmovilidad y su resolución apunta hacia dos direcciones: una interior, en el mundo rural, en la cordillera o a la orilla de los volcanes en donde nace esta especie, y otra exterior, hacia un afuera moderno y cosmopolita, el Estados Unidos en donde habita Jane. En ese vínculo, la relación con los pájaros así como las plantas, son ejemplares de revisar para pensar estas nuevas aproximaciones al cuerpo representado en Rojas y a las relaciones que desde él se construyen mediadas por la subjetividad de los personajes.

\section{III. "EL NIÑO Y EL CHOROY": ALIANZAS AFECTIVAS E INTER- ESPECIES}

En el archivo del escritor encontramos cuatro versiones del cuento inédito "El niño y el choroy", recientemente publicado en Cuentos completos (2019) 
por Alfaguara ${ }^{3}$. Para efectos de este artículo, recurrimos sin embargo a la transcripción realizada por Ignacio Álvarez, en la que se incluye la versión más acabada del texto y que, además, permite cotejarla con las otras variantes. Si bien en los documentos relativos a este relato no fue posible rastrear con exactitud la fecha de escritura de "El niño y el choroy", podemos mencionar que este se inserta en una serie de textos literarios y periodísticos de Rojas sobre pájaros. Estamos pensando en los cuentos "Una carabina y una cotorra", "Mares libres" y "Pancho Rojas", todos del año 1951, y algunos artículos publicados en Las Últimas Noticias en la década de los cuarenta, entre otras múltiples referencias a estos animales que circundan sus novelas, diarios de viajes y canciones. Este corpus no solo da cuenta de la fascinación del autor chileno por las aves y sus conocimientos acerca de estos animales, sino que además permite indagar en cómo Rojas piensa las relaciones entre seres humanos y no-humanos y sus propias tensiones vitales.

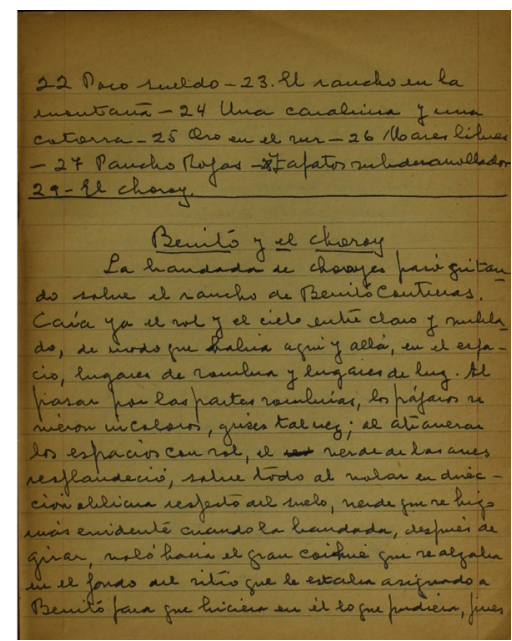

Cuaderno con uno de los manuscritos de "El niño y el choroy".

Archivo Manuel Rojas.

3 En el archivo existen dos manuscritos de este cuento en cuadernos distintos que reúnen materiales bastante heterogéneos. En uno de estos cuadernos (Doc. 06_01_09_01), en el que también se encuentra el manuscrito de "Una carabina y una cotorra", el texto recibe el título de "El choroy" y bajo este aparece tachado el título "La muerte del choroy". En el otro cuaderno (Doc. 06_02_03_01) el texto se titula "Benito y el choroy". Además, existen dos versiones mecanografiadas del cuento, ambas con algunas correcciones, y que llevan por título "El niño y el choroy" (Doc. 06_06_08_01 y Doc. 06-05-06-02). 
El cuento que aquí nos convoca narra la historia de una familia campesina que vive en una hacienda ganadera ubicada en el sur de Chile. Todo comienza con Benito Contreras, el padre de familia, quien escucha pasar una bandada de choroyes mientras trabaja en su rancho. Desde un inicio, el narrador se encarga de hacernos saber las precariedades materiales en que vive esta familia y cómo la presencia de estos pájaros se convierte en una esperanza nutricia e incluso económica: "El choroy, de alrededor de cuarenta centímetros de largo, bastante corpulento, es siempre, aunque de carne un poco dura, un buen plato, plato de comida que viene a animar el flaco menú de la mesa campesina, sin contar con que se puede venderlos o cambiarlos por algo" ( $\mathrm{s} / \mathrm{n}$ ). La llegada de los choroyes le hace recordar a Benito las ricas "cazuelitas" del año pasado y decide salir de caza al día siguiente. Con su escopeta preparada y escondido bajo un cobertizo de ramas, dispara hacia el cielo donde ve volar cientos de estas aves. Los niños le ayudan a recolectar los choroyes muertos y Benito -el menor de los hijos- se acerca a ver un loro que quedó vivo. Este le picotea el dedo y el padre decide matarlo; pero Juan, el hijo mayor, le ruega que no lo haga. A pesar de que todos -incluida la madre- están en desacuerdo, Juan se queda con el choroy herido. Lo cura y le pone por nombre Juan Chico. Como diríamos en buen chileno, el choroy se "ahuacha" en la casa de esta familia campesina y Juan lo cuida con cariño y lo protege de los puntapiés de su hermano. "Llegó el invierno, y Juanito Chico, de seguro ya fuerte, siguió en aquel rancho, rodeado de perros y niños, y dando alaridos de terror cuando alguien llegaba al rancho con una escopeta" $(\mathrm{s} / \mathrm{n})$, termina el relato.

En el contexto de una sociedad chilena en que aún perdura el régimen de la hacienda, Rojas nos invita en este cuento a pensar un nuevo parentesco o colaboración entre humanos y animales a partir de la relación que se establece entre Juan, un niño campesino, y el choroy herido, al que no por nada bautiza con su mismo nombre. Si bien el relato nos pone en presencia de un narrador omnisciente, la perspectiva infantil de este personaje ocupa un papel fundamental. De acuerdo con la crítica literaria Andrea Jeftanovic, lo más interesante de los relatos que buscan desplegar la subjetividad infantil poniendo en escena la voz o la mirada de los niños es que realizan un gesto impensable en nuestra realidad: "que los niños adquieran roles protagónicos y señalen arbitrariedades, denuncien injusticias y se rebelen contra el orden impuesto por lo mayores" (11). En el caso de "El niño y el choroy", cuando Juan solidariza con el loro pone en tensión las relaciones verticales que configuran su propia existencia. No solo desafía las jerarquías antropocéntricas entre hombre y animal, sino que además cuestiona las jerarquías de la institución 
familiar a la que pertenece. En cuanto hijo, se rebela en contra de la voluntad de sus padres y, como hermano mayor, no empatiza con el hermano menor herido sino con el loro que lo picoteó:

-No, papá -rogó-, no lo mates; yo lo voy a agarrar, yo sé agarrarlo, yo, yo.

Se sacó la delgada chaquetilla y acercándose al ave la cubrió con ella; luego, con precaución, la tomó. El ave lanzó dos o tres gritos, forcejeó un poco y en seguida, vista la inutilidad de sus esfuerzos, quedó inmóvil.

-Matémoslo mejor-sugirió Benito, luego de mirar el dedo del niño y estirando el brazo hacia el bulto.

-¡No, papá! ¡No lo matemos! -volvió a rogar Juan-. Quiero que sea para mí.

-¿Para qué quieres un choroy? -interrogó desabridamente la madreEs un pájaro bruto. No aprende nunca a hablar.

-No importa, mamita -suplicó de nuevo el niño-. Déjemelo (s/n).

En definitiva, lo que se observa en este diálogo y la actitud de Juan es un vínculo solidario y afectivo entre niño y pájaro, basado en la ética del cuidado. Surge, así, una pequeña comunidad inter-especies al interior de una familia tradicional de origen rural, conformada por subjetividades "otras" como lo son los niños y los animales, y desde la que se nos presenta la posibilidad de sostener una relación de respeto y colaboración con otros seres vivientes. El pequeño Juan ve en el choroy herido una vida que merece seguir viviendo y logra persuadir a sus padres para que lo dejen hacerse cargo de él. Algunos podrán contraargumentar que el niño convierte a este pájaro en un animal doméstico. Es cierto. El choroy se queda en la casa y depende de su pequeño amigo y guardián para alimentarse. Pero también es cierto que esta era la única posibilidad de mantener con vida a ese pájaro que había sido herido con un postón en una de sus alas. Rojas propone, entonces, la creación de lazos afectivos entre humanos y no-humanos como una respuesta o resistencia posible frente a la violencia humana ejercida en contra de la naturaleza y sus distintas formas de vida. Violencia infligida principalmente por personajes masculinos - pobres y ricos, campesinos y de ciudad, adultos y niños- y que muchas veces se sostiene en el uso de la técnica $u$ otros mecanismos de coerción.

En "El niño y el choroy", el maltrato animal se visualiza en dos situaciones concretas que, como ya hemos dicho, compete a distintos tipos de sujetos, sin 
distinciones de clase. Por un lado, tenemos a Benito Contreras, un hombre popular, campesino y padre de familia, que luego de cazar choroyes para alimentar a los suyos quiere matar a uno que ha quedado vivo por lastimar a su hijo de doce años. El narrador no emite juicios respecto a la caza de estas aves, pues comprende que allí se juega la sobrevivencia de una familia "siempre con ganas de comer y siempre con pocas probabilidades de hacerlo de modo siquiera mediocre" (s/n). Sin embargo, su relato deja entrever -a partir del actuar y las palabras de Juan- la crítica hacia una violencia humana que niega la vida a los seres considerados prescindibles o inferiores, en este caso, el choroy herido. Lo anterior resulta coherente con el artículo "Garzas blancas en Polpaico" (1945), en el que Rojas critica la matanza despiadada de las garzas, aves que debieron ser protegidas por ley para evitar su extinción:

Esta garza blanca fue, hasta hace pocos años, extraña y estúpidamente perseguida por comerciantes y aficionados a matar aves por gusto de matar, pues en Chile, y en todo el mundo, existen seres humanos, para deshonra de la especie, para quienes matar aves es una especie de destrucción espiritual. No hacen distinción entre un ave comestible -una perdiz o una codorniz, por ejemplo- y una que no lo es. La cuestión es matar (3).

Esas ganas de matar también movilizan a Benito Contreras, sujeto incapaz de entender que el choroy picoteó a su hijo no para hacerle daño, sino porque había sido atacado y estaba herido. El único que es capaz de empatizar con esa situación de vulnerabilidad extrema es Juan. De ahí esta alianza entre aves y niños que también se insinúa en cuentos como "Pancho Rojas", donde el padre de familia sostiene que son sus hijos los más indicados para enterrar al queltehue recién muerto que tenían como mascota: "Era preciso enterrarlo en alguna parte del jardín, pero no debía hacerlo yo; deberían hacerlo los niños, que estaban más cerca que yo del ave, libres y un poco salvajes aún, aunque no tanto como Pancho Rojas: mi paternidad ya los había manoseado un poco" (397). Ahora bien, es importante puntualizar que en los relatos de Rojas no todos los niños tienen esa sensibilidad especial por la naturaleza. Tal es el caso del pequeño Benito, quien no logra olvidar ni comprender -al igual que su padre y tocayo- la herida que le hizo el choroy: "el resultado fue un odio casi homicida contra el choroy, odio que manifestaba por tal o cual puntapié dado al loro cada vez que podía, y no siempre podía, pues Juan vigilaba" (s/n). Nuevamente se repite ese "gusto de matar" descrito por Rojas 
en su artículo sobre las garzas, que viene a fisurar cualquier idealización o romantización en torno a la infancia.

El otro caso de maltrato animal se hace presente de una forma más solapada en "El niño y el choroy". La familia Contreras vive en el campo, es decir, son sujetos que -suponemos- mantienen una relación cotidiana con distintos tipos de animales, a diferencia de lo que ocurre en las sociedades modernas y urbanas. Estamos hablando de animales capaces de proveer los alimentos y materiales necesarios para sobrevivir y con los que también se establece una relación afectiva y de cuidados. Siguiendo a John Berger, podríamos conjeturar que son "hombres [que] dependían de los animales para el alimento, el trabajo, el transporte, el vestido" ( $\mathrm{s} / \mathrm{n})$. Sumado a lo anterior, hacia la mitad del cuento el narrador explica que la hacienda donde vive y trabaja Benito y su familia es una hacienda ganadera que se dedica a la producción de carne, alimento que a su vez opera como una marca o distintivo de clase: "Junto con los choroyes desapareció la poca gordura adquirida y tuvieron que volver a la harina y a las papas, en una región en donde lo que hay, fuera de agua y bosques, son animales, rebaños de reses cuya carne está destinada a bocas privilegiadas, que no son las de los trabajadores de las haciendas ganaderas" $(\mathrm{s} / \mathrm{n})$. El fragmento pone en tensión dos maneras de relacionarse con los bienes proveídos por la naturaleza. Por un lado, tenemos a los inquilinos que hacen frente a la pobreza alimentándose de sus propias cosechas y los animales que cohabitan con ellos, dando cuenta de una lógica de subsistencia sustentable basada en el autosustento comunitario. Desde una vereda opuesta, tenemos a los sujetos acomodados que comen la carne que esos mismos campesinos producen, pero a la que ellos no pueden acceder. Es la lógica del capital que, como bien explica el personaje del Salteador Chico en "Mares libres", se sostiene en la siguiente paradoja: algunos viven "de los bienes y del trabajo ajenos" (387).

Desde esta perspectiva, se advierte en el cuento "El niño y el choroy" una crítica hacia la transformación de los animales en meras materias primas destinadas al consumo de unos pocos y que además se sostiene en la explotación de los trabajadores rurales. En otras palabras, no solo las vacas son bestializadas y cosificadas por la industria ganadera, sino también los seres humanos que trabajan en dicho rubro. Quienes comen esa carne no ven al animal ni tampoco al campesino que está detrás de ese alimento. En este sentido, la hacienda ganadera puesta en escena por Rojas viene a representar la ruptura entre humanos y animales que la modernidad propicia y que, como bien sostiene Berger en su ensayo ya citado, se manifiesta en la marginación 
y reducción de los animales "a unidades aisladas de producción y consumo" $(\mathrm{s} / \mathrm{n})$. Quizá de una manera algo indirecta, esta mirada rojiana acerca de la industria ganadera está en sintonía con las prácticas naturistas que cultivaron algunos anarquistas de principios de siglo XX y que dicen relación con la adopción de una dieta vegetariana (Lagos Mieres 348-349). Así lo describe Rojas en La oscura vida radiante, cuando Aniceto Hevia conoce a José Encarnación y otros anarquistas que frecuentaban una pensión porteña:

Y comían allí otras personas, invitadas por esa noche o pensionistas regulares; pagaban algo o aportaban su propia comida, atados de rabanitos o de zanahorias, brazadas de espinacas y de acelgas, docenas de cebollas o de betarragas, kilos de porotos, tajadas de zapallo, sandías cuando era verano, manzanas en otoño, duraznos en primavera, paltas en invierno, lo que encontraban o lo que les gustaba, de todo menos carne, nada de cadáveres (125).

Pero hay algo más. La hacienda ganadera en que Rojas sitúa su relato da cuenta también de la ruptura entre seres humanos marcada por las diferencias sociales o de clase, las que por cierto están atravesadas también -aunque de manera menos explícita en el relato- por asimetrías de género y etarias. Desde esta perspectiva, la pequeña comunidad conformada por los dos Juan, el niño $\mathrm{y}$ el choroy, funciona como una suerte de modelo para pensar las relaciones entre humanos, incluso al interior de una institución de por sí jerárquica y adultocéntrica como lo es la familia. Relaciones creadas sobre la base del cuidado, la reciprocidad, la colaboración y la protección del más débil o de aquellos que portan una herida (como Aniceto en Hijo de ladrón).

De esta manera, podemos decir que "El niño y el choroy" es un cuento que pone de relieve la posibilidad de pensar lo humano desde lo animal y específicamente desde los pájaros, seres que en la obra rojiana siempre se vinculan con una experiencia de libertad deseada y la posibilidad de transitar o deambular sin los obstáculos de las fronteras o los certificados de la burocracia. De ahí que la identificación de Juan con el choroy no sea casual. Quizá en este animal y la bandada de choroyes el niño proyecta una libertad que, en su condición de hijo de inquilino, es decir, al alero de un patrón y sin tierra propia, no posee del todo. Ni él ni su familia. Al mismo tiempo, este relato inédito abre la posibilidad de pensar lo humano y lo animal como una zona liminar o fronteriza, en la que niños y pájaros pueden crear alianzas y vínculos profundos, capaces de interpelarnos acerca de nuestra propia existencia y cómo nos relacionamos con otros. 


\section{A MODO DE CIERRE}

Tanto en Astromelia como en "El niño y el choroy", la organización de los textos y su temática abren la lectura a una subjetividad alternativa -la de Pedro Orellana y la astromelia, la de Juan y el choroy-que se construye en vínculo con otros seres vivos y que proyecta su experiencia desde esa relación afectiva, colaborativa y abierta. Por una parte, la evocación de la flor a la que se accede desde la casa por medio de la imagen y, por otra, el cuidado del choroy en la actitud solidaria de Juan, ofrecen una red de descripciones y atributos que dedican a los otros seres vivientes un lugar preponderante en la literatura, construyendo una aprehensión de la naturaleza dotada de una vida íntegra y en vínculo con el resto del ecosistema y no solo al servicio de los humanos. En ambos casos, este vínculo consolida afectos que se expresan en sus protagonistas, quienes buscan y aprenden de la naturaleza rompiendo la jerarquía en que el hombre es dominador de la flora y la fauna. Esto queda demostrado en la ruptura con la hegemonía de la hacienda ganadera, en el caso del cuento, y la relación alegórica entre la astromelia, Jane y los pájaros como seres libres exentos de las constricciones de la casa y el mundo familiar. Por consiguiente, el orden en que la razón humana asegura la superioridad de la especie se ve, al menos, fracturado. La amistad es en esta vía una forma asociativa valorada en la literatura rojiana y que, en ejemplos como los acá analizados, es una alianza esclarecedora para los personajes. Este vínculo puede ser también repensado ya no solo como exclusivo entre seres humanos, sino que extendido a humanos y animales o humanos y flora. Es en la identificación de la amistad que se construye un mundo valioso e inclasificable que desafía la retórica del poder.

“Cómo clasificamos las cosas? Cánido, homínido; mascota, profesora; perra, mujer; animal, humana; deportista, cuidadora" (Haraway, Cuando 39), se pregunta Donna Haraway. Ese cuestionamiento en torno a "Las Grandes Divisiones" (39) de la cultura que configuran nuestro proceso de subjetivación y de relacionarnos con otros se vincula, a nuestro parecer, con el archivo. En tanto a priori de enunciados, la apertura material y simbólica de los archivos de escritores y escritoras nos da pie a nuevas apropiaciones y, por lo mismo, a la disputa de una identidad siempre móvil y divergente, que se reconoce en nuevas y más propicias clasificaciones. Si las comunidades alternativas de las que nos habla Rojo representan una vía posible desde las visiones de anarquistas y obreros, pensamos que esas comunidades pueden ampliarse en un mundo en que las humanidades y las ciencias cuestionan con fuerza 
el antropocentrismo y se preguntan por alternativas para alcanzar una vida libre y justa en coherencia con el ecosistema. De este modo, el pensamiento ecologista parece más que necesario. Reducir la aprehensión de la naturaleza, los seres humanos y sus vínculos con otras vidas a una cuestión premoderna o atemporal, simplifica el problema en una polarización que no es productiva ante el complejo panorama que hoy estamos viviendo. Entender a Rojas como un pasante (Amaro), y con él podríamos tomar muchas otras literaturas como la de Mistral o Brunet, nos da amplitud para abordar la discusión que estas literaturas imaginan en la organización del mundo y las relaciones con otros en un panorama que no escapa a la modernidad, sino que la enfrenta, tensiona y resignifica.

Lejos de ser un filósofo posthumanista o un activista ambiental, Rojas intuyó -y probablemente también lo aprendió de sus lecturas de Henry David Thoreau y William Henry Hudson- que todos y todas somos naturaleza. Leyó a los naturalistas, observó cuidadosamente a los pájaros, cruzó la cordillera a pie con solo dieciséis años, caminó al aire libre, hizo excursiones a la montaña con sus amigos e hijos, y antes de morir fue a El Quisco a ver el mar por última vez. Como bien explica Manuel Lagos Mieres; "Para los anarquistas era fundamental el contacto con la naturaleza y la vida sana; eran pues estos paseos campestres, formas de ver realizado dicho proyecto, abriendo a la vez un espacio de sociabilización y ocupación del tiempo libre" (288). Efectivamente, Rojas encontró en las escapadas al cerro de fin de semana y los veranos en Cahuil una forma de volver a reconectarse con la naturaleza y una línea de fuga frente a una vida que, poco a poco, se había vuelto rutinaria y sedentaria. Si bien fue un sujeto urbano, Manuel Rojas vivió en y con la naturaleza y aprendió de ella formas posibles y más humanas de relacionarse con otros, que ponen en entredicho las jerarquías de control y sometimiento. Además, descubrió en ella la reconquista de un cuerpo ya no pensado desde la lógica de la productividad o la sobrevivencia, sino desde la práctica de la escritura, la experiencia de los sentidos, el ritmo impuesto por la caminata, el frío de la cordillera o el goce de sentir el chorrito de agua sobre la espalda.

La lectura que aquí hemos desarrollado en torno a dos textos inéditos de Rojas, Astromelia y "El niño y el choroy", nos abre a nuevas dimensiones del diálogo crítico acerca de autores canónicos de nuestra literatura. Confiamos en que mantener ese espíritu constante de intercambios es una didáctica de aprendizajes conjuntos que desafía la hiperespecialización, como dirá Rita Segato en Contra-pedagogías de la crueldad, capaz de devolvernos el goce por los cruces o los nuevos parentescos y que nos dispone a zonas no previamente clasificadas. 


\section{BIBLIOGRAFÍA}

Álvarez, Ignacio y Stefanie Massmann. "Vínculo social e identidad en la primera narrativa de Manuel Rojas”. Estudios Filológicos 47 (2011): 7-21.

Amaro, Lorena. "Pasadores de fronteras: Manuel Rojas y José Santos González Vera”. Chasqui. Revista de Literatura Latinoamericana 44.2 (2015): 21-32.

Areco, Macarena. "La novela de lo abierto de Manuel Rojas". Manuel Rojas: una oscura y radiante vida. Eds. María José Barros y Pía Gutiérrez. Santiago: Ediciones UC, 2020. 117-132.

Berger, John. “PPor qué miramos a los animales?”. Página 12. 23 feb. 2003. Consultado de https:/www.pagina12.com.ar/diario/suplementos/radar/subnotas/638-122-2003-02-23.html

Carreño, Rubí. "Las huertas de Mistral y Urriola: conversando con las plantas y los muertos". Taller de Letras 65 (2019): 163-171.

Ernst, Wolfgang. "The archive as a metaphor. From archival space to archival time" (2004). Consultado de https://www.onlineopen.org/download.php?id=366\#: :text=45\%20 (1939).\&text=The $\% 20$ 'archive'\%20has\%20become $\% 20$ one,of $\% 20$ memory $\% 20$ and $\% 20$ storage $\% 20$ agencies.\& text $=$ Non $\% 2$ Ddiscursive $\% 20$ practices $\% 20$ are $\% 20$ the, the $\% 20$ codes $\% 20$ behind $\% 20$ computer $\% 20$ software.

Espinoza, Enrique. Manuel Rojas. Narrador. Buenos Aires: Babel, 1976.

Jeftanovic, Andrea. Hablan los hijos. Discursos y estéticas de la perspectiva infantil en la literatura contemporánea. Santiago: Cuarto Propio, 2012.

Guerrero, Javier. "Sobre la piel: Reinaldo Arenas y Severo Sarduy en contacto". Cuadernos de Literatura 42 (2017): 23-48.

Haraway, Donna. Seguir con el problema. Generar parentesco en el Chthuluceno. Trad. Helen Torres. Bilbao: Consonni, 2016.

"Cuando las especies se encuentran: introducciones". Tabula Rasa 31 (2019): 2375. Consultado de https://doi.org/10.25058/20112742.n31.0

Lagos Mieres, Manuel. Experiencias educativas y prácticas culturales anarquistas en Chile (1890-1927). Santiago: Centro de Estudios Sociales Inocencio Pellegrini Lombardozzi, 2018.

Mösbach, Ernesto Wilhelm de. Botánica Indigena de Chile. Santiago: Museo Precolombino de Chile, DIBAM, 1986.

Oyarzún, Luis. "Flores silvestres de Chile". Defensa de la tierra. Valdivia: Ediciones UACh, 2020. 53-54.

Rojas, Manuel. "Los cincuenta y nueve años de Acevedo Hernández”. Las Últimas Noticias. Santiago, 10 mar. 1944.

“Garzas blancas en Polpaico". Las Últimas Noticias. Santiago, 17 ene. 1945.

"Pancho Rojas". Cuentos completos. Santiago: Alfaguara, 2019. 393-398.

"Mares libres". Cuentos completos. Santiago: Alfaguara, 2019. 381-391.

La oscura vida radiante. Santiago: LOM, 2007.

"El niño y el choroy". Transcripción y cotejo de Ignacio Álvarez. 
Astromelia. Archivo Manuel Rojas. Doc 06_01_24_01.

Rojo, Grínor. "La contraBildungsroman de Manuel Rojas". Revista Chilena de Literatura, sección Miscelánea (2009).

Segato, Rita. Contra-pedagogías de la crueldad. Buenos Aires: Prometeo, 2018.

Solnit, Rebecca. Wanderlust. Una historia del caminar. Santiago: Hueders, 2015.

Soto Calderón, Andrea. La performatividad de las imágenes. Santiago: Ediciones Metales Pesados, 2020.

Viu, Antonia. "El orden de los cuerpos: la caminata en Imágenes de infancia y adolescencia y A pie por Chile". Manuel Rojas: una oscura y radiante vida. Eds. María José Barros y Pía Gutiérrez. Santiago: Ediciones UC, 2020. 69-83. 